\title{
Erratum to: Water management strategies for hydropower annexation at existing irrigation dams in Japan
}

\author{
Tatsuki Ueda $^{1} \cdot$ Masahiro Goto $^{1} \cdot$ Atsushi Namihira $^{1} \cdot$ Yuichi Hirose $^{1}$
}

Published online: 24 January 2017

(c) The International Society of Paddy and Water Environment Engineering and Springer Japan 2017

\section{Erratum to: Paddy Water Environ (2015) 13: 229-240 DOI 10.1007/s10333-014-0432-4}

In the original publication of this article, Table 2 header has been mentioned incorrectly. Now the correct header is provided in this erratum.

In Table 2 (page 237), percentile discharges on line 1 marking the rated discharges should be: $Q_{\max }, Q_{\mathrm{t} 10}, Q_{\mathrm{t} 20}$, $Q_{\mathrm{t} 30}, Q_{\mathrm{t} 40}, Q_{\mathrm{t} 50}$ and $Q_{\mathrm{t} 60}$, instead of: $Q_{\mathrm{max}}, Q_{\mathrm{t} 20}, Q_{\mathrm{t} 30}, Q_{\mathrm{t} 40}$, $Q_{\mathrm{t} 50}, Q_{\mathrm{t} 60}$ and $Q_{\mathrm{t} 70}$.

In addition to that, the text in the following lines must be modified according to the above changes in the header, which means each of $Q_{\mathrm{t} 20}, Q_{\mathrm{t} 30}, Q_{\mathrm{t} 40}, Q_{\mathrm{t} 50}, Q_{\mathrm{t} 60}$ and $Q_{\mathrm{t} 70}$ appearing in the original text should be replaced by $Q_{\mathrm{t} 10}$,
$Q_{\mathrm{t} 20}, Q_{\mathrm{t} 30}, Q_{\mathrm{t} 40}, Q_{\mathrm{t} 50}$ and $Q_{\mathrm{t} 60}$, respectively. Line 54 in page 236; lines $3,5,6,7,10$ in page 237; lines 2, 5 in page 238; lines 5, 13, 14, 28, 42 in page 239; and the legend of Fig. 8 (page 238).

In addition, the sentence on line 52 page 236 should be read as: therefore, the rated discharge $Q_{\mathrm{r}}$ varies from $Q_{\max }$ to $10,20, \ldots, 60$ percentile discharges $Q_{\mathrm{t} 10}, Q_{\mathrm{t} 20}, \ldots, Q_{\mathrm{t} 60}$ evaluated in Fig. 7. And the following sentence (line 54, page 236) should be erased: (10 percentile values are omitted as they are exactly the same as the 20 percentile values.

The authors regret the mistakes would appear extensively and confuse the readers.

The online version of the original article can be found under doi:10.1007/s10333-014-0432-4.

Tatsuki Ueda

tued@affrc.go.jp

1 National Institute for Rural Engineering, National Agriculture and Food Research Organization, 2-1-6 Kannondai, Tsukuba, Ibaraki 305-8609, Japan 